\title{
VIDAPRODUCTIVAY PRINCIPALES CAUSAS DE DESCARTE DE VACAS HOLSTEIN EN LA CUENCA DE LIMA
}

\author{
Jorge Orrego A. ${ }^{1}$, Alfredo Delgado C. ${ }^{2}$ y Luisa Echevarría C. ${ }^{3}$
}

\section{AbSTRACT}

Records of 3,100 culled Holstein cows from 10 dairy herds in the Lima valley during the period of 1990 till 1996 were analyzed to determine the age at first calving, number of lactations and length of the productive life as well as the main reasons for culling. In the analysis was considered herd size ( $>500$ cows, $100-500$ and $<100$ cows) and type of farm (private and cooperative). Culling reasons were grouped in problems relating to fertility, udder, feet, calving, emergency, and others. The age at first calving, number of lactations and length of the productive life was $28.6 \pm 4.1$ months, $3.0 \pm 2.0$ and $42.9 \pm 29.4$ months, respectively. Statistical differences due to herd size was not found ( $p>0.05)$ with the exception of age at first calving which was lower in herds with more than 500 cows $(27.9$ $\mathrm{m} \mathrm{p}<0.05)$. Cows from cooperatives showed an older age at first calving, larger number of lactations and longer productive life $(\mathrm{p}<0.05)$. The main reasons for culling were: fertility $(52.7 \%)$, udder $(12.1 \%)$, feet (3.0\%), calving (3.5\%), emergency (8.7\%), and others $(19.9 \%)$.

Key words: productive life, dairy cattle, culling reasons

\section{RESUMIEN}

Se analizó los registros de 3,100 vacas Holstein que fueron descartadas de 10 establos lecheros de crianza intensiva en Lima durante los años 1990 a 1996 con el propósito de determinar la edad al primer parto, el número de lactancias y la vida productiva de los animales así como las principales causas de descarte. En el análisis se consideró el establo, el tamaño del hato (>500 vacas, de 100 a 500 y <100 vacas) y el tipo de empresa (accionariado reducido y múltiple). Las causas de eliminación fueron agrupadas por problemas de fertilidad, de ubre, del aparato locomotor, peripartales, emergencia y otros. La edad al primer parto, el número de lactancias y la vida productiva fue de $28.6 \pm$ 4.1 meses, $3.0 \pm 2.0$ y $42.9 \pm 29.4$ meses, respectivamente. No se encontró diferencias significativas por efecto de tamaño de establo $(\mathrm{p}>0.05)$ con excepción de la edad al primer parto que fue menor en establos con más de 500 vacas $(27.9 \mathrm{~m}, \mathrm{p}<0.05)$. Los animales de los establos con accionariado múltiple tuvieron una mayor edad al primer parto, un mayor número de lactancias y un mayor tiempo de permanencia en el hato $(\mathrm{p}<0.05)$. Las distribución de las causas de descarte fueron: $52.7 \%$ por problemas reproductivos, $12.1 \%$ por problemas de ubre, $3.0 \%$ por problemas del aparato locomotor, $3.5 \%$ por problemas peripartales, $8.7 \%$ por motivos de emergencia y $19.9 \%$ por otras razones.

Palabras clave: vida productiva, vaca lechera, causas de descarte

\footnotetext{
${ }^{1}$ Práctica privada

${ }^{2}$ Clínica de Animales Mayores, FMV-UNMSM. E-mail: adelgadoc@vet.unmsm.edu.pe

${ }^{3}$ Laboratorio de Reproducción y Obstetricia Veterinaria, FMV-UNMSM
} 


\section{INTRODUCCIÓN}

El periodo de vida productiva corresponde a la etapa comprendida entre el primer parto y la eliminación del animal del hato lechero (Battistini, 1958), siendo sinónimo de longevidad y producción vitalicia (Maldonado, 1991). Otros autores consideran que la longevidad refleja la habilidad de una vaca para no ser eliminada por baja producción, baja fertilidad o enfermedad (Vollema, 1996), la cual puede afectarse por errores en el manejo reproductivo (Ferguson, 1995). La longevidad también se puede estimar en el número de lactaciones completas o en años de edad. A mayor número de lactaciones de la vaca, más largo será el periodo en que el ganadero podrá amortizar su inversión (Balth et al., 1987).

Trabajos anteriores en el país indican una vida productiva de $3.7 \pm 1.0$ años para la cuenca lechera de Lima (Dextre, 1961) y $4.6 \pm 2.6$ años para la cuenca de Cajamarca (Pando, 1969).

En un estudio realizado en 7 establos de la cuenca de Lima se encontró que sólo el $57 \%$ de los animales llegan a tener 4 partos (Salazar, 1993), mientras que en otro estudio realizado en Cajamarca con ganado semiestabulado se reportó un $22.3 \%$ de descarte de vacas por infertilidad o fallas reproductivas (Pando, 1969). Por otro lado, años atrás se reportó que las principales causas de descarte de las vacas lecheras en Lima fueron por trastornos reproductivos (49.6\%), baja producción $(21.8 \%)$ y tuberculosis bovina (19.7\%) (Dextre, 1961). Otras observaciones en Lima señalan que la mayor frecuencia de causas de descarte es debido a problemas reproductivos y baja producción láctea (Castagnino, 1983).

La edad al primer parto es un factor muy importante en la vida productiva de la vaca; así, el parto de vaquillonas a los dos años de edad en comparación a partos con edades más avanzadas repercute en una mayor producción láctea y conduce a un menor consumo de alimento, derivando un menor costo inicial de crianza (De Alba, 1964; Huertas y Cedeño, 1976). Actualmente no existen razones biológicas para retrasar el parto de vaquillas más allá de 24 meses (Patrick, 1996).

En vista de no existir información actualizada, se realizó el presente estudio con el objetivo de determinar el periodo de vida productiva de vacas Holstein y analizar las principales causas de descarte de los rebaños en la cuenca de Lima.

\section{MatidRiales y Mó́todos}

Se trabajó con las fichas individuales de 3,100 animales descartados de 10 establos ubicados en la cuenca lechera de Lima entre 1990 a 1996. Los establos tenían vacas Holstein bajo un sistema de crianza intensiva, alimentación basada en forraje y alimento balanceado, inseminación artificial, ordeño mecánico (dos ordeños al día, con excepción de un establo con tres ordeños).

Los establos se clasificaron por tamaño poblacional en tres grupos:

- Grupo A: >500 vacas

- Grupo B: entre 100 a 500 vacas

- Grupo C: <100 vacas

Y por el tipo de empresa se clasificaron en:

- Empresa de accionariado reducido

- Empresa de accionariado múltiple

Las causas de eliminación fueron agrupadas teniendo como referencia el trabajo de Milián (1991), donde se considera como vacas descartadas a aquellas que salieron en pie del establo, dejando de lado las vacas postradas o muertas en el establo, y a aquellas que no tenían registrado correctamente las causas de su eliminación. 
Las causas de descarte fueron agrupadas como sigue:

1) Problemas reproductivos: abortos, infecciones del aparato reproductor, fetos momificados, infertilidad, esterilidad (no incluye casos de emergencia).

2) Problemas de ubre: infecciones de ubre, cuartos perdidos, ubre con ligamentos vencidos (no incluye casos de emergencia).

3) Problemas del aparato locomotor o traumatismos: cojeras, infecciones de la pezuña, problemas en la cadera.

4) Problemas peripartales: trastornos metabólicos (hipocalcemia, acetonemia), partos distócicos y complicaciones secundarias.

1) Problemas de emergencia con riesgo de muerte: leucosis enzoótica bovina, traumatismos de peritoneo y corazón, pericarditis, neumonía fulminante, infecciones sistémicas con mastitis por coliformes o estafilococos de curso hiperagudo, toxemias, peritonitis aguda.

6) Otros: Reactores positivos a pruebas serológicas, tuberculosis, timpanismos, insuficiencia cardiaca congestiva, intoxicaciones, enfermedades de origen hereditario (síndrome espástico). Además, vacas vendidas para recría, intervenidas por cirugía, o con una baja producción láctea.

Se utilizó el análisis estadístico de regresión múltiple (GLM). Se combinó la información de dos establos con características similares, por lo que sólo se consideró nueve (9) establos en el análisis.

Las variables dependientes fueron vida productiva, lactancia y edad al primer parto; las variables independientes fueron tamaño del hato, establo y tipo de empresa. Las causas de descarte se expresan como frecuencias.

El análisis de la información se realizó en el Laboratorio de Reproducción y Genética y en la Clínica de Animales Mayores de la Facultad de Medicina Veterinaria de la Universidad Nacional Mayor de San Marcos.

\section{Resultados}

La duración de la vida productiva de las vacas en estudio fue de $42.9 \pm 29.4$ meses (promedio \pm d.e.). El número promedio de lactaciones durante la vida productiva fue de $3.0 \pm 2.0$, y la edad al primer parto de las 3,100 vacas descartadas fue de $28.6 \pm 4.1$ meses.

Los animales de empresas con accionariado múltiple a diferencia de aquellas con accionariado tuvieron un mayor número de campañas lácteas, un mayor tiempo de permanencia de las vacas en el establo, y una mayor edad al primer parto $(\mathrm{p}<0.05)$ atribuible a una menor presión de selección y manejo administrativo (Cuadro 1).

Las frecuencias y razones de descarte de vacas en los establos bajo evaluación se muestran en el Cuadro 2. En el cuadro no se incluye los 149 registros de animales que fueron descartados por encontrarse postrados o por haber muerto en el establo, ni tampoco los 651 registros de animales que fueron descartados sin que se haya consignado la razón específica. Estos casos representaron el 5.2 y $22.8 \%$ del total de registros evaluados.

\section{Discusión}

Se considera que las 3 primeras campañas son vitales para recuperar la inversión realizada por una vaca lechera (Ferguson, 1995). De considerarse válida esa afirmación se tendría que sólo el $33 \%$ de vacas representarían utilidades al ganadero.

Los trastornos de la fertilidad se constituyen en la principal causa, seguidos de los trastornos de la glándula mamaria. Estas causales 
Cuadro 1. Edad al primer parto, número de lactancias y vida productiva en vacas lecheras de la cuenca de Lima que fueron descartadas en el periodo 1990-1996. ( $\mathrm{n}=$ $4,000)$

\begin{tabular}{lcc}
\hline \multirow{2}{*}{ Variable Productiva } & \multicolumn{2}{c}{ Establo con Accionariado } \\
\cline { 2 - 3 } & \multicolumn{1}{c}{ Reducido } & Múltiple \\
\hline Edad al primer parto (m) & $27.9 \pm 0.1^{1 \mathrm{a}}$ & $30.0 \pm 0.1^{\mathrm{b}}$ \\
Vida productiva (n) & $38.3 \pm 0.6^{\mathrm{a}}$ & $52.6 \pm 1.0^{\mathrm{b}}$ \\
Número de lactancias & $2.8^{\mathrm{a}}$ & $3.6^{\mathrm{b}}$ \\
\hline
\end{tabular}

${ }^{1} \mathrm{CM} \pm$ error estándar

${ }^{a b}$ Promedios con letras desiguales dentro de filas son estadísticamente diferentes $(p<0.05)$

Cuadro 2. Principales causas de descarte de vacas lecheras de la Cuenca de Lima en el periodo 1990-1996

\begin{tabular}{cccccccc}
\hline \multirow{2}{*}{ Establo } & $\begin{array}{c}\text { Descartes } \\
(\mathrm{n})\end{array}$ & \multicolumn{7}{c}{ Causa de descarte $(\%)$} \\
\cline { 3 - 8 } & \multicolumn{1}{c}{1} & 2 & 3 & \multicolumn{1}{c}{4} & \multicolumn{1}{c}{5} & \multicolumn{1}{c}{6} \\
\hline 1 & 649 & 49.8 & 9.4 & 2.6 & 3.2 & 8.9 & 26.0 \\
2 & 117 & 61.5 & 2.6 & 1.7 & 11.1 & 10.3 & 12.8 \\
3 & 248 & 54.4 & 20.6 & 2.8 & 4.0 & 4.4 & 13.7 \\
4 & 28 & 60.7 & 14.3 & 3.6 & 0.0 & 14.3 & 7.1 \\
5 & 71 & 42.3 & 38.0 & 2.8 & 4.2 & 0.0 & 12.7 \\
6 & 19 & 52.6 & 21.1 & 0.0 & 10.5 & 10.5 & 5.3 \\
7 & 9 & 44.4 & 11.1 & 0.0 & 33.3 & 0.0 & 11.1 \\
8 & 18 & 72.2 & 5.6 & 0.0 & 0.0 & 0.0 & 22.2 \\
9 & 237 & 51.1 & 7.72 & 4.2 & 4.6 & 14.8 & 18.1 \\
10 & 655 & 54.7 & 12.4 & 3.4 & 1.2 & 8.6 & 19.9 \\
\hline Total & 2,051 & 52.8 & 12.2 & 3.0 & 3.5 & 8.7 & 19.9 \\
\hline
\end{tabular}

1. Problemas reproductivos

2. Problemas de ubre

3. Problemas del aparato locomotor

4. Problemas peripartales

5. Causas de emergencia

6. Otras causas 
representan el $65 \%$ de los motivos de descarte.

La media de descarte para problemas relacionados a ubre fue de $12.2 \%$; sin embargo, el comportamiento entre establos fue muy variado. Los establos grandes registraron valores razonablemente bajos $(9.4 \mathrm{y}$ $12.4 \%)$, lo que indicaría que en este tipo de establecimientos habría un mejor manejo para el cuidado de la ubre.

En las causas de eliminación a través de los años, se observa un incremento en los trastornos de la fertilidad y esto tendría relación con el desafío hacia la alta producción, pues la tecnología de la alimentación ha sido siempre un objetivo de los productores de leche; sin considerar a los problemas que de ella resultan, especialmente en los trastornos de la reproducción con una media de $52.7 \%$ para los 7 años. Las otras causas de eliminación no tienen una distribución ascendente como los trastornos de la fertilidad.

Adicionalmente el 5.2\% del total de animales evaluados correspondío a aquellos que son descartados por encontrarse en estado de postración y a aquellos que murieron en el establo, quizás por no haber recibido una atención terapéutica en el momento adecuado o porque en algunos casos no responden adecuadamente al tratamiento ante un estado hiperagudo de determinado trastorno.

Las causas de eliminación deberían ser por razones voluntarias del productor (baja producción láctea, mala conformación anatómica o por modificaciones en el tamaño del hato), evitando las causas de descartes involuntarios como problemas de salud o reproductivos, pezuñas, patas, problemas de ubre y mastitis; siendo conveniente para este caso un buen manejo del hato (Ferguson, 1995), donde se involucre un programa sanitario y reproductivo adecuado a la realidad de cada establo.

\section{Conclusiones}

- El promedio de vida productiva en los establos lecheros es de $42.9 \pm 29.4$ meses.

- Las principales causas de descarte son los problemas de fertilidad y alteraciones de la ubre.

- Los registros de los establos no incluyen las causas exactas de descarte de sus animales en una importante proporción.

\section{Literatura Citada}

1. Balth, D.L.; F.N. Dickinsonn; H.A. Tuker. 1987. Ganado Lechero. $2^{\text {da }}$ ed. $p$ 450. Ed. Interamericana. México.

2. Battistini, V.E. 1958. Estudio sobre algunos aspectos relativos a la reproducción del ganado Holstein en el establo de Maranga. Tesis Bachillerato. Facultad de Zootecnia, Universidad Nacional Agraria La Molina. Lima. 96 p.

3. Castagnino, O. 1983. Algunos factores que influyen sobre la eficiencia reproductiva de vacas en establos bajo control lechero de la Asociación de Criadores Holstein Registrado del Perú, 1981-1982. Tesis Bachillerato. Facultad de Medicina Veterinaria, Universidad Nacional Mayor de San Marcos. Lima. 39 p.

4. De Alba, J. 1964. Reproducción y genética animal. IICA-OEA. Costa Rica. $320 \mathrm{p}$.

5. Dextre, E. 1961. Edad al primer parto, longevidad y motivos de eliminación de las vacas lecheras en el valle de Lima. Tesis Bachillerato. Facultad de Medicina Veterinaria, Universidad Nacional Mayor de San Marcos. Lima. 39 p.

6. Ferguson, J. 1995. La reproducción en hatos lecheros. Rev. Hoard's. Diciembre. p 1138.

8. Huertas, E.; G. Cedeño. 1976. Ganado de leche. Manual de Asistencia Técnica $\mathrm{N}^{\mathrm{o}}$ 6. Instituto Colombiano Agropecuario, ICA. 30 p. 
9. Maldonado, S. 1991. Curvas de crecimiento y su relación con la productividad de por vida en vacunos Holstein. Tesis de Bachillerato. Facultad de Zootecnia, Universidad Nacional Agraria La Molina. Lima. 105 p.

10. Milián, F. 1991. Principales razones de desecho en un hato lechero de 1000 vacas. Revista Veterinaria México 22: 169175.

11. Pando, L. 1969. Edad al primer parto, longevidad y motivos de eliminación de las vacas lecheras en la campiña de Cajamarca. Tesis de Bachillerato. Facultad de Medicina Veterinaria, Univ. Na- cional Mayor de San Marcos. Lima. 38 p.

12. Patrick, H. 1996. Las vaquillas bien alimentadas tienen partos normales a los 22 o 24 meses. Rev. Hoard's Dairyman. Mayo. $\mathrm{p} 450$.

13. Salazar, A. 1993. Parámetros reproductivos y observación de celos en la cuenca lechera de Lima. Tesis de Bachillerato. Facultad de Medicina Veterinaria, Univ. Nacional Mayor de San Marcos. Lima. 47 p.

15. Vollema, 1996. Genetic parameters of longevity traits of an upgrading population of dairy cattle. J. Dairy Sci. 79: 22612267. 